\title{
UNA CUARTA VERSIÓN DE LA CAPITULACIÓN DE TUDMTR
}

Por

ALFONSO CARMONA GONZÁLEZ

Universidad de Murcia

Como es bien sabido, en la primavera del año 713 (1), si creemos las fuentes árabes disponibles, 'Abdal'aż̄z $b$. Mūsá, jefe de uno de los ejércitos islámicos que procedían entonces a ocupar la Península lbérica, otorgó a Teodomiro, señor de la región levantina que luego sería conocida como Tudmīr, unas favorables condiciones de armisticio, reflejadas en un documento de sulh. El término árabe sulh, que se puede aplicar a negocios jurídicos y pleitos de diversa índole, es traducible por «transacción», «acuerdo» o «pacto». Se trata desde el punto de vista de la jurisprudencia islámica, de un contrato mediante el cual las partes, haciéndose mutuas concesiones, es decir, abandonando un derecho a cambio de una compensación, evitan un litigio o ponen fin al ya comenzado. La palabra șulh aparece en el Corán (4:114 y $4: 127 / 128)$ en su sentido más general de «reconciliación», «concordia» 0 «arreglo amistoso".

También es suficientemente sabido que de dicho documentos nos han llegado varias copias o versiones. La primera de la que tuvo noticia la historiografía no-árabe de la Península Ibérica fue en realidad la transmitida por Ahmad ar-RāzT (ob. 955), que era conocida desde finales del siglo XIII cuando se tra-

(1) Cf. P. Balaña Abadía: «La fecha exacta de la capitulación de Tudmîr, un error de transmisión», AWRĀQ, 4, Madrid, 1981, pp. 73-77. Sobre el Pacto de Teodomiro existe una abundantísima bibliografía; el lector me habrá de perdonar (o me agracederá) que sólo cite lo que considero especialmente útil para el objetivo del presente trabajo. Puede consultarse el documentado trabajo sobre el estado de esta cuestión en 1975 (por lo tanto, no del todo anticuado) de E. Molina López y Elena Pezzi de Vidal: «Últimas aportaciones al estudio de la cora de Tudmir (Murcia). Precisiones y rectificaciones" en Cuadernos de Historia del Islam, 7, Granada, 1975-76, pp. 83-109. 
dujo al portugués la obra de ar-Rāzi llamada Ahbār mulūk al-Andalus, cuyos materiales fueron aprovechados poco después para la redacción de la Crónica de 1344. Ambas obras fueron traducidas al castellano en los siglos siguientes. La información referente al Tratado de Orihuela, aunque se ha perdido tanto en el original árabe de los $A h b \bar{a} r$ de ar-Rāzi como en su traducción romance, subsiste en la Crónica de 1344 y en la "versión" de la Crónica del Moro Rasis realizada en el siglo XVII por Gabriel Rodríguez de Escabías adicionando diversos materiales, conocida como el «manuscrito de Copenhague».

En este último manuscrito, el pasaje relativo a la Capitulación de Teodomiro responde fielmente a lo que podemos leer en la Crónica de 1344, que a su vez "traducía» la Historia de ar-Rāzi. El que la referencia al Tratado de Orihuela responde a un original árabe se puede comprobar si se compara dicho texto (que reproduzco a continuación) con cualquiera de las versiones del Pacto que nos han llegado:

«E $\left[\right.$ Abelancin $={ }^{\circ}$ Abdal'azíz] lidio con la gente de Orihuela e de Lorca e de Valencia e de Alicante, e quisso Dios assi que los vencio. E dieronle las villas por pleitessia, e ficieronle cartas de seruidumbre en que Abelancin los defendiesse e amparasse, e non partiesse los fijos de los padres, nin los padres de los fijos sinon por su placer dellos; e que obiessen su auer como lo auian assi en el campo como en las villas, e que cada vno de los que en ellas morassen le diese la mitad de la dezima parte que al año su facienda valiese, e mas quatro almudes de trigo e quatro de ordio, e miel e azeyte como lo cogiessen vna parte señalada; e jurase Abelancin que non denostaria a ellos ni a su fee, nin les quemasse sus iglesias, e que los dejasse guardar su ley. $E$ todo se lo prometio e se lo otorgo e fizo sus juramentos de non se lo quebrantar. E quando estas cartas fueron assi fechas andaba la era de los moros en nobenta e quatro años» (2).

Advertimos en el texto anterior varias novedades con respecto a las versiones del Pacto en árabe: "la mitad de la dezima parte que al año su facienda valiesse» en lugar de «un dinar»; "que obiessen su auer ... en el campo como en las villas», detalle no mencionado en ninguna otra parte. Por estas razones y dado que este pasaje no reproduce literalmente, en toda su formalidad, el texto del Tratado, y que, además, no nos ha llegado el original árabe, no se suele tener en cuenta en el cómputo de las versiones literales, o al menos fiables, del Pacto que nos han llegado.

Así pues, se considera que la primera versión conocida por la historiografía moderna europea fue la que aparece en la obra de aḍ-Ḍabbī (ob. 1203), dada a conocer por M. Casiri en 1770 (3) con algunos recortes y algún error de lectura, e íntegramente a finales del siglo XIX: en 1881 por J. Lerchundi y F.J. Simonet (4) y en 1885 por F. Codera y J. Ribera en su edición de la Bugyat almultamis (5).

(2) Crónica del Moro Rasis, ed. D. Catalán y M.S. de Andrés, Madrid, 1975, p. 359.

(3) Bibliotheca Arabico-Hispana Escurialensis, II, Madrid, 1770, p. 106.

(4) Crestomatía arábigo-española, Granada, 1881, p. 84-85.

(5) Tomo III de la Bibliotheca Arabico-Hispana, Madrid, 1885, p. 259. 
La segunda versión que la historiografía contemporánea ha podido manejar es la contenida en el diccionario geográfico-histórico ar-Rawd al-Mi ${ }^{\circ} \operatorname{a} a r$ (6) de al-Himyari, editada hace medio siglo. Existen dudas sobre la personalidad de este autor y, por lo tanto, sobre la fecha de redacción de la obra. Probablemente hubo una primera versión de ar-Rawd al-Mi ${ }^{\circ} t \bar{a} r$, debida a un miembro de la familia al-Ḥimyar̄T que vivió entre los siglos XIII y XIV, mientras que la redacción definitiva del libro cabe fecharla en 1461.

La tercera versión de que han sabido nuestros historiadores es la que se

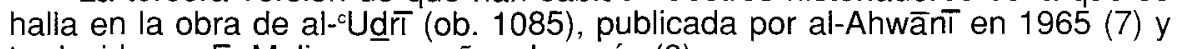
traducida por $E$. Molina unos años después (8).

Así pues, en las últimas décadas, los investigadores y estudiosos de la conquista árabe de España y de la Historia del Sarq al-Andalus han venido manejando tres versiones del llamado Pacto de Teodomiro.

Por otro lado, son conocidas también algunas otras fuentes que aluden a la citada Capitulación sin transcribir su contenido. Es el caso del Kitāb al-Filāha de Abū Bakr ar-Rāzī, quien dice, según cita az-Zuhñ (9), que «sus habitantes [los de Tudmir] pactaron (tașālaḥu) con Mūsà b. Nușayr» y da a entender que dicho pacto fue respetado, lo que explicaría, según él, la baraka, la especial bendición de que goza la tierra de Murcia.

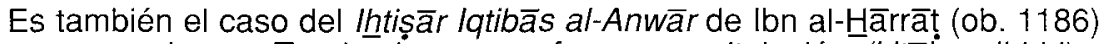
(10), que menciona a Teodomiro y a su famosa capitulación (kitäb sulhi-hi) y nos ofrece la lista de la siete ciudades, las mismas que en el texto de aḍDabbī, lo cual no nos debe extrañar ya que lbn al-Hāarrạt resume el texto -hòy perdido- de ar-Ruš âți (ob. 1147) y que este último fue maestro de aḍ-Ḍabbi (11), quien lo cita frecuentemente en su Bugyat al-multamis, por lo que podemos concluir que aḍ-Dabbī sin duda copió la versión de ar-Ruš ațī, nacido en la misma ciudad en que fue firmado el famoso Tratado.

Finalmente, E. Molina anuncia «haber hallado [...] la versión latina de dicho Tratado a través de la Crónica Continuatio Hispana» (12).

Estos eran nuestros conocimientos sobre las fuentes acerca de la Capitulación de Orihuela cuando, a mediados de la década de los ochenta, hallé que existía una «cuarta» copia del Pacto de Teodomiro, que había sido editada en 1925 y que nunca había sido utilizada ni citada por quienes se han venido ocupando de esta cuestión. Es decir, que había permanecido ignorada por nuestra historiografía durante sesenta años.

(6) Ed./trad. de E. Lévi-Provençal: La Péninsule Ibérique au Moyen Age d'après le Kitāb al-Rawḍ al-Mi țăr Leiden, 1938.

(7) Fragmentos geográfico-históricos de al-Masālik ilà ğamī al-Mamālik, Madrid, 1965, pp. 4-5.

(8) La cora de Tudmīr según al--Ud̆ī..., en Cuadernos de Historia del lslam 4, Granada, 1972, pp. 58-60.

(9) Kitāb al-Gacrafiyya, ed. M. Hadj Sadok, Damasco, 1968, p. 207.

(10) Al-Andalus en el Kitāb lqtibās al-Anwār y en el litișār lquibās al-Anwār, ed. E. Molina López y J. Bosch Vilá, n.ำ de la colección Fuentes Arábico-Hispanas, Madrid, 1990, p. 130.

(11) Véase E. Molina López: "El Kitāb Intișār lqtibās al-Anwār de lbn al-Harrāt. El autor y la obra...", en Quaderni di Studi Arabi, 5-6, Venecia, 1987-88, p. 556.

(12) En el trabajo citado en la nota anterior, p. 556, nota 35. 
Se trata de la versión que aparece en la obra de Abū I-Qāsim Muhamad aš-Sar̄if al-Garnāțī: Kitāb Raf al-h̆uğūb al-mastūra $\pi$ mahāasin al-Maqșūra (13). Se trata de uno de los comentarios que recibió la célebre Al-Qașida alMaqșūra de Hāazim al-Qarțāğannī. Su autor nació en Ceuta en 1297 y murió en Granada en 1359 (14). Probablemente copió el texto del Pacto de la misma fuente que ad-Dabbî: de ar-Rušâț̂, a quien cita en la misma página en que transcribe dicha Capitulación, a propósito de una opinión sobre la etimología del topónimo Sevilla (texto, este último, que aparece en el lhthtişār lqutibās).

Informado del hallazgo, E. Molina aludió en 1986, en el Congreso de la UEAl en Venecia, a la existencia de esta última versión y adelantó que Robert Pocklington y yo teníamos terminado un trabajo conjunto sobre la Capitulación de Tudmīr. Efectivamente, dicho estudio existía e incluía el texto de la última versión hallada. El trabajo fue entregado para su publicación, pero, por razones que desconocemos, nunca ha sido impreso.

Por mi parte, anuncié por primera vez este hallazgo en mi estudio de 1987 sobre al-Qarțăğannī (15), remitiéndome, para más detalles, al trabajo conjunto inédito antes citado. También R. Pocklington mencionó el descubrimiento de esta nueva versión, en su conocido artículo sobre «el emplazamiento de lyi(h)» (16).

En 1989, en su discurso de ingreso en la Real Academia de la Historia, Joaquín Vallvé dio noticia también del descubrimiento de esta fuente ignorada (17).

Por lo tanto, desde 1925, antes de la difusión de las obras de al-Himyari y de al-¿Ud $r T$, existía un nuevo texto impreso del Tratado, aunque ello pasó desapercibido para quienes entonces se ocupaban de la Historia de al-Andalus. $\mathrm{Ni}$ el mismo E. García Gómez, que publicó en 1933 un trabajo sobre la Qāșĩa Maqșüra y su Comentario por al-Garnāț (18), parece haber caído en la cuenta de ello. Por lo que hubo que esperar 12 años más para que la publicación del Rawḍ de al-Huimyarī «corroborara» el texto de aḍ -DabbT.

La razón de este «olvido» parece estar en la poca difusión que, entonces y ahora, ha tenido entre nosotros la edición del Comentario de al-GarnāțT.Por ello, parece oportuno reproducir esta "cuarta" versión del célebre Pacto de Teodomiro, que ofrezco aquí acompañada de mi propia traducción.

Como el lector podrá comprobar, esta versión del célebre tratado se emparenta con las de ad-DabbT̄ y al-Himyañ̄, que presentan evidentes diferencias con la de al-cUdñ̄. Ásí pues, tenemos al menos dos riwāyas o transmisio-

(13) Ed. El Cairo, 1344/1925, t. II, p. 167.

(14) Más datos sobre este sabio en E. García Gómez: “Observaciones sobre la "Qașida Maqșūra" de AbūI-Hasan Hāzim al-Qarțâyanni', en Al-Andalus 1, Madrid-Granada, 1933, p. 85.

(15) En Historia de Cartagena, t. V, Murcia (Ediciones Mediterráneo), 1987, p. 505 y nota 14.

(16) En Sharq al-Andalus 4, Alicante, 1987, p. 178

(17) Nuevas ideas sobre la conquista árabe de España. Toponimia y onomástica, Madrid, 1989, pp. 106-7.

(18) «Observaciones sobre la "Qașìda Maqșūra" de Abū-I-Ḥasan Hāzim al-Qarțâyannì, en Al-Andalus 1, Madrid-Granada, 1933, pp. 81-103. 
nes del texto. Si juzgásemos por la traducción medieval castellana que hemos transcrito se podría concluir que el texto de ar-Rāzī presentaba a su vez notables divergencias con ambas y, por tanto, constituiría una tercera riwāya.

La relación de ciudades acogidas a la capitulación (suplidas las omisiones de los topónimos Laqant e lyih o lyu(h), y corregidas las malas lecturas de Balantala (¿Valentula?), que aparece como B.n.tila, y de Buqașra (Begastri, junto a Cehegín) que es transcrito como B.nira o B.nayra), es la misma que aparece en ar-Ruš ățT (19) y en aḍ-DabbT, y prácticamente la misma que en al'Ud nos proporciona al-HimyarT, aún con los problemas de transmisión del texto -problemas a los que me he referido en otro lugar (20)-, puede sostenerse que es también la misma que dio a conocer ar-Rušạț.

La lista de testigos del documento ofrece algunas variantes con respecto al texto de add-Dabbī (como se sabe, el de al-HimyarT omite la relación de testigos, y al-`Udín aporta ocho nombres, de los que sólo los dos primeros y el último coinciden de algún modo con los de la lista de aḍ-Ḍabbī y al-Garnāțī).

(19) Ed. E. Molina y J. Bosch, Madrid, 1990, p. 130.

(20) “Yakka, Ğumalla, Bilyāna» en Yakka. Revista de Estudios Yeclanos, 3, 1991, pp. 15-6. 


\section{TEXTO ÁRABE}

Kitāb Raf́ al-ḩugūub al-mastura tt mahāisin al-Maqșūra de Abū I-Qāsim Muhammad al-GarnāțT.

$$
\text { t. } 11, \text { p. } 167
$$

كتاب من عبد العزيز بن موسى بن نصير لتدمير بن عبدوس أنه نزل على الصلع وان

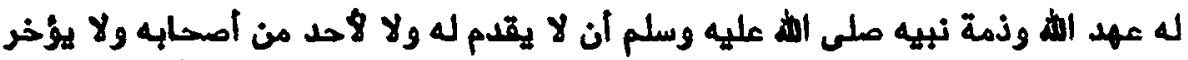
ولا ينزع عن ملكه وأنهم لا يقطون ولا يسبون ولا يفرق بينهم وبين أولادهم ولا نسائهم

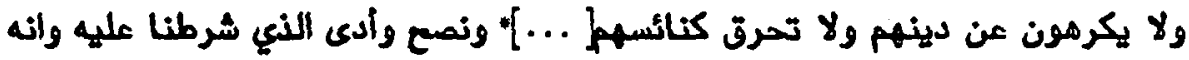

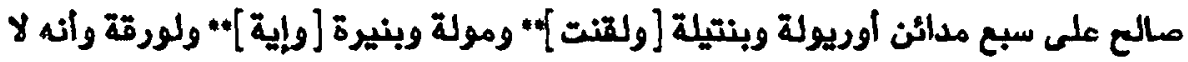

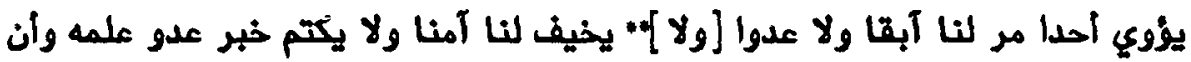

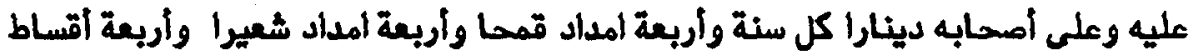

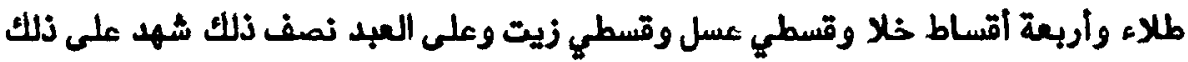

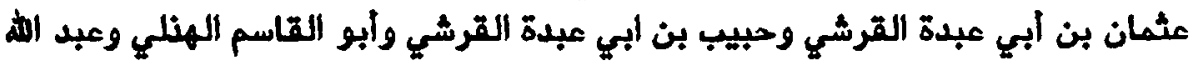

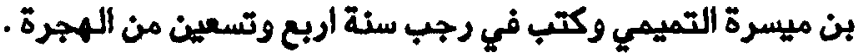

- El editor advierte que, en el texto original, hay un espacio en blanco que debe corresponder a unas cuatro palabras. Estas muy probablemente son las que aparecen, en ese lugar, en los textos de aḍ-Dabbi y al-Ḥimyari: ولا ينزع من ملكه ما تعبّذ.

* Falta en el original. Restituyo de acuerdo con los textos de ad-Dabbi y al-Himyari. 


\section{TRADUCCIÓN}

“Escritura que otorga (min) ${ }^{\circ} \mathrm{Abd}$ al- ${ }^{\mathrm{C} A z \bar{I} z}$ b. Mūsà ibn Nușayr a (Ii) Tudmīr (Teodomiro) b. 'Abdūs [en que le reconoce] que éste se ha rendido mediante capitulación (nazala calà s-sulh) y se acoge al Pacto instituido por Dios (la-hu cahd Allahh) y a la protección (dimma) de Su Profeta, que Él bendiga y salve (21), que le garantizan que no cambiará su status o posición ni el de ninguno de los suyos (as hābi-hi) ni se le privará de su dominio (22), y que no serán matados, ni reducidos a esclavitud, ni separados de sus hijos o sus mujeres, ni forzados a abandonar su religión, ni se les quemarán sus iglesias.

"[No será despojado de su dominio mientras] (23) sea leal y respete las condiciones que le hemos impuesto. Él capitula en nombre de (wa-annahu sālaha calà) siete ciudades, que son Uryūla (Orihuela), B.n.tīla, [Laqaant], Müla (Mūla o Mola), Bntra o B.nayra, [ly.h] y Lürqa (Lorca). No deberá dar cobijo a nadie que huya de nosotros, ni a ningún adversario nuestro; no atacará a nadie que tenga nuestro amān o salvaguardia; no nos ocultará ninguna noticia acerca del enemigo que llegare a su conocimiento. Quedan obligados, él y los suyos, a entregar cada año un dinar, cuatro almudes de trigo, cuatro de cebada, cuatro medidas de mosto, cuatro de vinagre, dos medidas de miel y dos de aceite; los siervos deberán pagar la mitad de las cantidades antedichas.

"Fueron testigos del documento: 'Utmān b. AbT 'Abda al-QurašT, HabTb b. AbT 'Abda al-QurašT, Abū l-Qāsim al-Hudari y 'Abdallāh b. Maysara at-TamīmT.

„Fue redactado en el mes de rağab del año 94 de la Hégira».

(21) Los términos ahd y dimma indican el marco jurídico islámico, el marco institucional, en que se va a desarrollar la vida de esta comunidad cristiana levantina que se ha acogido a la capitulación (șulh). Cf. M. de Epalza: "Descabdellament politic i militar dels musulmans a terres catalanes (segles VIII-XI)" en Symposium internacional sobre els origens de Catalunya, Barcelona, 1991, pp. 55-59.

(22) La palabra aquí empleada, $m . k$, puede leerse mulk y milk; en el primer caso, habría que interpretarla como «soberanía, autoridad", y en el segundo como «propiedad, hacienda". Del contexto del documento se desprende que a Teodomiro se le garantizan ambas cosas, por lo que empleo en mi traducción el término «dominio» en el sentido tanto de «poder que uno tiene de disponer libremente de lo suyo" como de "superioridad legítima sobre las personas". No obstante, teniendo en cuenta que las mismas fuentes que transcriben el Pacto llaman a Teodomiro malik «rey", habrá que entender que lo que aquí se le garantiza es la conservación de su poder real (mulk).

(23) Ésta es la traducción de las palabras que -creo- suplen la laguna advertida por el editor en el original. Del mismo modo, añado luego, también entre corchetes, los nombres de las dos ciudades omitidas, en el orden que les corresponde según la lista de ar-Rušăti, reproducida por aḍ-Ḍabbi. 